\title{
Festival Internacional "La música en el Di Tella" (Resonancias de la modernidad) y homenaje al CLAEM -Centro Latinoamericano de Altos Estudios Musicales-en su $50^{\circ}$ aniversario
}

\author{
por \\ Eduardo Cáceres R. \\ Facultad de Artes, Universidad de Chile, Chile \\ kazeres@gmail.com
}

He tenido el altísimo honor de asistir y participar en este $50^{\circ}$ aniversario, en un festival que reunió a quienes -en su momento- en la década del 70 eran los alumnos-becarios del CLAEM y constituían sólo "promesas". En su gran mayoría ellos son reconocidos en la actualidad como los grandes compositores de nuestro continente, muchos con trascendencia internacional.

Este festival se realizó entre el 17 y el 24 de junio de 2011. Las actividades se efectuaron principalmente en el excelente Centro Cultural Borges, e incluyeron conciertos de cámara, obras electroacústicas, conferencias y mesas redondas. Asimismo, en el auditorio de Belgrano se realizaron conciertos de música sinfónica. Ambos establecimientos se ubican en la ciudad de Buenos Aires, Argentina.

El Instituto Di Tella de Buenos Aires resonaba desde hace muchos años en los oídos de los compositores de nuestra generación en Chile y obviamente con mucha fascinación por parte de quienes participaron en esos diez años de experimentación, aprendizaje y creación. Se podrían clasificar básicamente en cuatro promociones, desde el año 1961-62 hasta el año 1970. Cada promoción abarcó una duración aproximada de dos años.

Sabemos, por cierto, que el principal gestor en la realización de este proyecto fue el compositor Alberto Ginastera, quien con la colaboración de grandes figuras como Gerardo Gandini y Francisco Kröpfl, entre otros, llevaron adelante el "Di Tella”. Gandini y Kröpfl asistieron parcialmente esta vez al festival, básicamente por problemas de salud.

La organización estuvo a cargo de la Secretaría de Cultura de la Nación Argentina y su director artístico fue el compositor Eduardo Kusnir.

La destacada colaboración y aporte del Director Nacional de Artes, José Luis Castiñeira de Dios, junto a la eficiente coordinación de la productora ejecutiva Micaela Gurevich, hicieron de este festival un encuentro y reencuentro del arte Revista Musical Chilena, Año LXV, Julio-Diciembre, 2011, N 216, pp. 102-104 
musical de nuestros compositores que nos convocó a todos desde una perspectiva de pasado y presente.

En el mismo Centro Cultural Borges se instaló una exposición permanente muy documentada con fotos de los compositores, videos e información biográfica relevante, así como también grabaciones en audífonos con obras de la época y reproducciones de partituras. Se destaca, ciertamente, la impresión de un catálogo muy completo, con documentación, memorias de los becarios, reflexiones, fotografías, programas de conciertos y biografías, entre otros aspectos ${ }^{1}$.

Desde el primer día de encuentro se produjo una situación difícil de describir, puesto que algunos compositores que fueron muy cercanos en aquella época no se volvieron a ver en los últimos 40 años. Se reencontraban casi con su pasado, pero con una visión de presente que los reubicaba en un nuevo contexto.

Se generaron muchos reencuentros entre los compositores asistentes a este evento durante la celebración del festival así como también entre muchos músicos provenientes de diferentes países y que en su momento fueron protagonistas de los cursos del Di Tella. Por cierto hasta lágrimas vi asomarse en varias ocasiones entre los participantes. También percibí diferentes tipos de emociones, algunas a favor de la amistad y el reencuentro y otras opuestas y contradictorias por situaciones pendientes, no resueltas debido al marco en que se generaron estos cursos en su época y su propio contexto político y cultural que abrieron diferencias estéticas y posturas irreconciliables.

No todos llegaron, algunos no pudieron y otros ya están fallecidos. Sin embargo la presencia de una gran mayoría de ellos se impuso. Tuvimos junto a nosotros a compositores que alcanzaron relieve internacional y que han posesionado su trabajo creativo en las últimas décadas.

Para mí fue un motivo de gran alegría encontrarme con varios compositores que he conocido en festivales tanto en nuestro continente como en Europa o en mi propio país (Chile), siempre con un espíritu altamente identitario de América y especialmente de los países de habla hispana y portuguesa, incluyendo especialmente Centro y Sudamérica.

Asistieron a este festival -y con mucho entusiasmo- Mesías Maiguashca (Ecuador y Alemania), Alcides Lanza (Argentina-Canadá), Alberto Villalpando (Bolivia), Armando Krieger (Argentina), Blas Emilio Atehortúa (Colombia), Miguel Ángel Roldano (Argentina), Jorge Sarmientos (Guatemala), Gabriel Brncic (Chile-España), Mariano Etkin (Argentina), Rafael Aponte-Ledée (Puerto Rico), Graciela Paraskevaídis (Argentina-Uruguay), Miguel Letelier (Chile), Coriún Aharonián (Uruguay), Joaquín Orellana (Guatemala), Jorge Antunes (Brasil), y los argentinos Eduardo Kusnir, Luis Arias, Luis María Serra, Mario Perusso y Jorge Arandia.

${ }^{1}$ José Luis Castiñeira de Dios (director). La música en el Di Tella: resonancias de la modernidad, Buenos Aires: Secretaría de Cultura de la Presidencia de la Nación, 2011, 160 p.

Versión digital en la dirección web: <http://issuu.com/festivalclaem/docs/claem_cat-160 pags-23x29_web> 


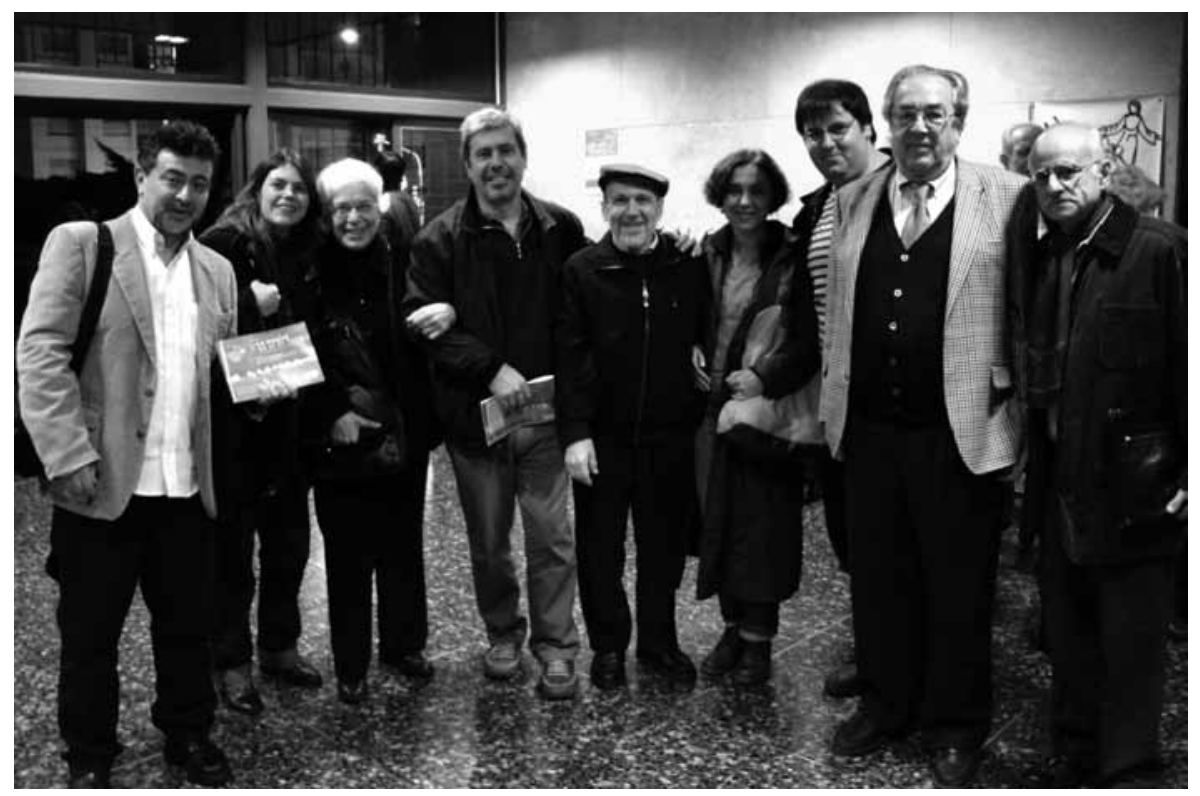

Eduardo Cáceres, María Cecilia Villanueva, Graciela Paraskevaídis, Carlos Mastropietro, Coriún Aharonián, Leandra Yulita, José Manuel Serrano, Miguel Letelier, Mariano Etkin.



Claudio Barile, flauta; Carlos Vega, contrabajo; Gastón Frosio, corno; Mariano Etkin, compositor.

La programación de conciertos del Festival alcanzó a un total de ocho conciertos y cuarenta y seis obras, que abarcaron tanto música de cámara como música sinfónica. 